\title{
Abstracts from the literature
}

\section{Sympathetic effects of aminophylline}

Theophylline is thought to act by inhibiting the activity of phosphodiesterase, with a resultant increase in intraccllular cyclic AMP. However, this concept is largely based on in vitro studies using concentrations of theophylline which greately exceed therapeutic plasma concentrations. To investigate the relationship of the cardiovascular and metabolic effects of theophylline to activation of the sympathetic nervous system, i.v. aminophylline was administered to six healthy males under basal conditions. Each subject received four infusions. Mean theophylline concentrations ( \pm SEM) of 4.5 $\pm 0.2,10.0 \pm 0.5,14.0 \pm 0.5$ and $20.0 \pm$ $1.2 \mu \mathrm{g} \cdot \mathrm{ml}^{-1}$ were achieved. Plasma epinephrine increased 262 per cent (from $29 \pm 4$ to $105 \pm$ $14 \mathrm{pg} \cdot \mathrm{ml}^{-1}, \mathrm{p}<0.01$ ) and plasma norepinephrine increased 64 per cent (from $190 \pm 18$ to $312 \pm$ $51 \mathrm{pg} \cdot \mathrm{ml}^{-1}, \mathrm{p}<0,05$ ) during the high-dose infusion. The increases in circulating catecholamines were dose-related. Dose-related increases in heart rate, systolic blood pressure, plasma glucose, free fatty acids and insulin were also observed. Although the duration of total electromechanical systole $\left(\mathrm{QS}_{2}\right)$ and left ventricular ejection time adjusted for heart rate fell during the aminophylline infusions, this positive inotropic response was not influenced by dose, except possibly the high dose. Echocardiographic ejection fraction was not changed by the aminophylline infusions. The authors conclude that the acute cardiovascular and metabolic effects of theophylline may be mediated in part by stimulation of the sympathetic nervous system. (Vestal RD, Eiriksson CE. Musser B, Ozaki LK, Halter JB. Effect of intravenous aminophylline on plasma levels of catecholamines and related cardiovascular and metabolic responses in man. Circulation 1983; 67: 162-71)

\section{Beta blockers and pulmonary mechanics}

After a seven-day placebo lead-in period, one of three $\boldsymbol{\beta}$-adrenergic antagonists was taken for two weels by ten healthy male subjects. The drugs were metoprolol (cardioselective) and propranolol and nadolol (both nonselective). Dosage was according to currently recommended regimens and was increased after the first week (50 to $100 \mathrm{mg}$ b.i.d., 20 to $40 \mathrm{mg} \mathrm{q.i.d.,} \mathrm{and} 80$ to $160 \mathrm{mg}$ q.d.). Pulmonary mechanics and density dependence (DD) of maximal expiratory flow were measured before and at the end of the placebo lead-in period and the lowand high-dose treatment weeks. Total lung capacity (TLC), residual volume (RV), and RV/TLC all rose after high-dose nadolol. Forced vital capacity (FVC) and expiratory reserve volume fell after high-dose metoprolol. There was no change in forced expiratory volume in $1.0 \mathrm{sec}\left(\mathrm{FEV}_{1}\right), \mathrm{FEV}_{\mathrm{l}} /$ FVC, maximal midexpiratory flow rate, or airway resistance with any of the $\beta$-antagonists. Decreases in maximal expiratory flow determined at 50 per cent of the vital capacity occurred after propranolol and metoprolol, but not after nadolol. A doserelated decrease in DD at 50 per cent of the vital capacity accompanied nadolol dosing, but was significant only after the high-dose regimen. The decreases in DD with nadolol, as well as its effect on RV/TLC, are consistent with small airway narrowing. The findings with metoprolol and propranolol suggest that they affect central as well as peripheral airways. (Foley JE, Sigurdson MJ. Conliffe TF, Fand RS, Anthonisen NR. Effects of cardioselective and nonselective beta-adrenergic antagonists on pulmonary mechanics. Clin Pharmacol Ther 1982; $32: 149-55$.)

\section{Use of perfluorochemical oxygen-transport \\ fluid}

A perfluorochemical oxygen-transport fluid and plasma expander, Fluosol-DA was given to seven severely anaemic patients before surgery to determine its effectiveness in supplementing oxygen transport. The dose of Fluosol in the five patients completing the study was $20 \mathrm{ml}$ per kilogram of body weight. When the patients breathed low levels of supplemental oxygen (mean partial pressure of arterial oxygen $\pm S D, 101 \pm 25$ torr), the per- 
fluorochemical carried a small amount of oxygen, but when they received pure oxygen (arterial oxygen pressure, $361 \pm 65$ torr) it carried approximately 0.8 per cent of oxygen (by volume). This increase accounted for $7 \pm 3$ per cent of the patients' arterial oxygen content and $24 \pm 7$ per cent of their oxygen consumption. The cardiac index and left ventricular stroke-work index decreased, whereas the oxygen delivery increased, although these changes were not statistically significant. Significant changes included a 22 per cent increase in oxygen consumption, a 59 per cent increase in mixed venous haemoglobin saturation to $90 \pm 6$ per cent. The authors conclude that at ambient oxygen tensions Fluosol acts primarily as a volume expander, whereas at higher tensions (>300 torr) it contributes substantially to the oxygen-delivery system. (Tremper KK, Friedman AE, Levine EM, Lapin $R$, Camarillo $D$. The preoperative treatment of severely anemic patients with a perfluorochemical oxygen-transport fluid, Fluosol-DA. N Engl J Med. 1982; 307; 277-83.)

\section{Aspirin usage and perioperative blood loss}

The effect of aspirin on perioperative blood loss was studied in 52 patients undergoing unplanned operation. Twenty-two patients were found to have taken aspirin prior to operation. Five others were suspected of having taken aspirin or some aspirin-like drug prior to operation. All patients who remembered taking aspirin preoperatively had significantly decreased platelet thromboxane $B_{2}$ levels caused by aspirin inhibition of platelet arachidonic acid metabolism. Eight of 22 patients who took aspirin had abnormal template bleeding times. No significant increase in perioperative blood loss was noted in patients who had taken aspirin. Neither the aspirin induced decrease in thromboxane $\mathbf{B}_{2}$ levels nor the increase in template bleeding times was associated with an increased perioperative blood loss. The authors conclude that aspirin is commonly used prior to unplanned operation but that preoperative aspirin usage does not result in increased perioperative blood loss in patients with normal platelet counts and with normal coagulation factors. These results suggest that there is no need to delay operation in this group of patients because of recent aspirin ingestion. (Ferraris VA, Swanson E. Aspirin usage and perioperative blood loss in patients undergoing unexpected operations. Surg Gynecol Obstet 1983; 156: 439-42.)

\section{Psychomimetic reactions after low-dose ketamine}

Low-dose ketamine anaesthesia was compared with neuroleptanaesthesia (droperidol $200 \mu \mathrm{g} \cdot \mathrm{kg}^{-1}$, fentanyl $5 \mu \mathrm{g} \cdot \mathrm{kg}^{-1}$, total doses) in respect of immediate and longer-term psychomimetic reactions, in 40 female patients undergoing elective gynaecological surgery. Qualitatively, but not quantitatively, different psychomimetic reactions occurred in both groups. In the neurolept group the predominant complaint was of a dissociative nature, reported after $24 \mathrm{~h}$ by 11 ( 55 per cent) of the patients, while in the ketamine group the predominant experience was dreaming, reported by eight ( 40 per cent) of the patients after $24 \mathrm{~h}$. Interviews after three months revesled a low frequency of psychomimetic reactions in both groups. However, 30 per cent of all the patients (12) complained of impairment of intellectual function, and in seven patients this was severe enough to interfere with their ability to work. (Klausen NO, Wiberg-Jorgensen $F$, ChraemmerJorgensen B. Psychomimetic reactions after lowdose ketamine infusion. Comparison with neuroleptanaesthesia. Br J Anaesth 1983; 55: 297-301.)

\section{Loss of nitroglycerin to cardiopulmonary bypass apparatus}

An in vitro model of a cardiopulmonary bypass (CPB) circuit using a bubble oxygenator was developed to assess the potential of this system to extract nitroglycerin (NTG). A NTG solution $(100 \mathrm{ng} / \mathrm{ml})$ was circulated through a $\mathrm{CPB}$ circuit at $5 \mathrm{~L} / \mathrm{min}$ for $60 \mathrm{~min}$. Samples obtained for NTG analysis revealed a significant loss of drug to the circuit. By 60 min, only 18 per cent of the initial NTG concentration was present. In a separate experiment, the bubble oxygenator was shown to be the major source of drug extraction, because less than 15 per cent of the drug concentration infused directly into the oxygenator appeared in the artcrial outlet. These results indicate that patients may not receive the expected dose of NTG during CPB even if caution is taken to administer the drug through nonadsorbing iv tubing. (Dasta $J F$, Jacobi $J, W u$ LS et al. Loss of nitroglycerin to cardiopulmanary bypass apparatus. Crit Care Med 1983; 11:50-2.) 